\title{
Socio-Economic Background of Saudi Society and Its Impact on the Financial Sector
}

\author{
Shahnaz Hamid ${ }^{1}$ \\ ${ }^{1}$ Prince Academy (Pures College of Technology Group), Canada \\ Correspondence: Shahnaz Hamid, Prince Academy (Pures College of Technology Group), Canada. E-mail: \\ shahnazhamid1@gmail.com
}

Received: March 6, 2014

Accepted: July 7, $2014 \quad$ Online Published: August 22, 2014

doi:10.5539/ijbm.v9n9p267

URL: http://dx.doi.org/10.5539/ijbm.v9n9p267

\begin{abstract}
The Financial sector in Saudi Arabia has experienced tremendous changes over the past few decades, especially due to the presence of oil. The socio-economic environment in this country has been confirmed to have a direct impact on the performance of the financial sector. The socio-cultural beliefs and practices have been blamed for the slow growth of this sector. The conservative culture towards women is seen as the main reason why some women are yet to embrace banking as a way of keeping their money. Other banking institutions give men superior services as compared to those given to women. This has discouraged some female customers, affecting the sector negatively. However, production and export of oil has supported this sector as business people, who come for the product, rely on the financial institutions to be able to trade. Tourism and agriculture have also supported this sector.
\end{abstract}

Keywords: discrimination, hikmat, mahram, shariah

\section{Introduction}

The Kingdom of Saudi Arabia is one of the largest countries in the Middle East, bordering Iraq, Jordan, Oman, Yemen, United Arab Emirates, Kuwait and Qatar. The country is largely an Islamic nation given the fact that most of its citizens are Muslims. According to Al-Mulhim (2009), Saudi Arabia has one of the fastest growing economies in the Middle East and the entire Arab World. The World Bank ranked it the largest economy in the Middle East in the year 2009. The socio-cultural practices of this country have largely been seen as unique, especially when compared to that of the Western countries. The Saudi society is uniquely Islamic, with most of the laws governing the country derived from the Shariah laws. The economy of the country has been stable even during the 2008 economic recession that affected many countries around the world. Although oil remains the leading source of income, other economic activities such as agriculture and tourism also play an important role in boosting the economy. The research by Tollitz (2005) has shown that the region has been experiencing impressive growth in trade with other parts of the world. The country has also embraced the open market policy, a fact that has enabled foreign firms to invest in the local economy. It would, therefore, be argued that the socio-economic environment in this society has had a positive impact on the financial sector. It would be of interest to determine the impact of this socio-economic environment on the financial sector.

\section{Literature Review}

Scholars have conducted considerable research about the socio-economic environment in Saudi Arabia, especially because of its strategic relevance in the world's energy sector. The Kingdom of Saudi Arabia has been considered the cradle land of the Islamic society. According to Nonneman (2006), Saudi Arabia is the heart of Islamic religion. The City of Mecca has a religious connotation to all Muslims across the world. When defining the socio-cultural practices of the Saudi society, Lacey (1982) says that it is important to understand the role of religion. The majority of the residents in the country are Muslims, practicing strict Islamic teachings as stipulated in the Shariah law. It is a fact that other religious groupings such as Christians and Hindus also exist in the country, but they constitute a negligible percentage. Their impact on this society would be considered inconsequential, given the fact that others are just visitors who come for trade or for a tour. This means that the social environment is closely defined by this religion. It would be important to understand how the social environment of this country affects the financial sector. 
According to Baamir (2010), many financial institutions operating in the Saudi society have been forced to learn the social dynamics in the society and develop products that would meet the needs of the locals in the best way possible. One of the defining cultural practices common in this country is the value given to men of this society. Although the society is slowly embracing equality of both genders, the truth is that it may take decades for true equality to be achieved. Men are still the custodians of the family wealth in the country. This means that they are the most attractive segment for the banks. Shoult (2006) says that this has had a negative impact on banks. Women prefer home banking where they can easily hide their money and retrieve it when they need it without being noticed, to avoid reprimand from their spouses who may want to know why they have bank accounts (Behdad \& Nomani, 2006).

Belanger (2011) says that in the Muslim society, men are not supposed to have body contact with women who are not their spouses. The Shariah law forbids this. The banking sector has grappled with this problem for a long time because in the banking halls, it may not be easy to avoid body contact (Kent \& Thompson, 2005). This forced many women to avoid banking as a way of eliminating chances of having body contact with men. As Lippman (2012) observes, this reduced the number of customers who visited the banks, reducing their profitability. Other firms that were keen to attract both male and female customers were forced to create different banking halls for the two groups (Lippman, 2004).

Samba Financial Group is one such institution that has developed male and female banking in its Riyadh and major cities in the country. Although this has earned the bank admiration among the Muslim society as a bank that seeks to uphold Islamic teachings, it comes at an extra cost that would have been used for other development purposes (Cordesman, 2003). The bank has to establish two banking halls in these major cities in an attempt to attract both male and female customers. Although this is working in the local economy, Robertson (2005) says that the bank may risk developing a negative image in the international society. Saudi Arabia has been criticized for upholding conservative laws towards women. For instance, Krivenko (2009) notes that women of this country were not permitted to drive cars just because they were women. They could also travel abroad only after being granted permission from their mahrams. Their husbands could deny them the permission at will. Some were even forced to ask the permission from their sons in case they did not have husbands, because the society considered them as people who lacked hikmat (Rubin, 2005).

The retrogressive belief has been criticized by the world society, and there has been pressure on the government and the society in general to eliminate such retrogressive laws and cultural practices. Developing another bank that is distinctively meant for women will bring the need to compare the service delivery of the two banking units. As mentioned above, men are still the custodians of family wealth, and it would be common to find men in banking halls with better facilities for faster service delivery (Tripp \& North, 2003). This will give a negative image in the international society. As Long (1997) says, the outsiders may not realize that the bank was forced to develop different banking halls because of the social environment in the country. There will be a belief that the firm is trying to promote a culture that is oppressive to women, which may affect the bank's performance in non-Islamic regions where it has branches such as in the United Kingdom. Banking institutions have also had problems with the issue of interests earned on customer's deposits. As Clinton (2011) notes, customers will always be convinced to bank their money when they know their money will earn some interest. However, Shariah law does not approve such interests. Some staunch Muslims still consider banking as an institution that is meant to bring temptation to humanity that can make them sin against Islamic teachings (Kline, 2010). This has also had a negative effect on the financial sector in the country.

According to Madawi (2006), the impact of the economic environment on the financial sector in Saudi Arabia has been positive. Saudi Arabia still remains the leading exporter of oil in the world. This has made major cities, such as Riyadh, strategic trading points in the world. International society has to visit the country in search of oil. This has boosted the financial sector because it offers the medium through which financial transactions can take place. Many of the traders, who frequent the country, have opened bank accounts with local financial institutions to ease their financial transactions (Mai, 2005). The religious significance of the City of Mecca has also boosted the financial sector. Hundreds of thousands of tourists visit this city every year. Their frequent visits have made some of them open bank accounts with local banks. These tourists also boost other business entities, which will in turn improve their banking. The country also has an active agricultural sector that has been playing a major role in stabilizing the economy. Some of the farm produce is exported to neighboring countries, earning foreign exchange to the country. This helps in strengthening the financial sector. Based on findings from the relevant literature, the following null and alternate hypotheses were developed:

H1o: The social-cultural environment in Saudi Arabia has no negative impact on the financial sector. 


\section{H1a: The social-cultural environment in Saudi Arabia has negative impact on the financial sector.}

H2a: The economic environment in Saudi Arabia has no positive impact on the financial sector.

H2a: The economic environment in Saudi Arabia has a positive impact on the financial sector.

H3o: The religious practices in Saudi Arabia have not boosted the financial sector.

H3a: The religious practices in Saudi Arabia have boosted the financial sector.

It is important to understand the diversity in this society in terms of religious beliefs, gender, and other demographic factors, and how this affects the economic system of this country. Saudi Arabia is an Islamic country. Over $98 \%$ of the natives are Muslims, with the Jews, Christians and other religions hardly making one percent of the population. Sunni Muslims make the majority of the population, accounting for over $85 \%$ of the nationals. Women in this society are still viewed as subordinate to men. They are not supposed to perform certain duties without permission from their husbands. This is a major hindrance to their development, especially as professionals (Cordesman, 2003). The citizens of this country live above the poverty line. However, this scholar notes that there are those who are super rich and a number who are living below the poverty line. The aliens make a good percentage of those living in Saudi Arabia. There are those who are in this country for job purposes, which increases the number of non-Muslims. Long (1997) observes that the country is governed based on the Islamic laws. Because of this, the scholar says that other religious groups find it increasingly difficult to cope. Because of the presence of oil reserves in this country, many individuals from various countries have been attracted to trade. They need financial institutions that can facilitate their businesses. Muslims from across the world view Saudi Arabia as their cradle land. They highly cherish its two cities of Mecca and Medina (Baamir, 2010). As the above scholar states, the country is the central nervous system of the Arab world.

Although oil is still the main income earner in this society, tourism currently plays an important role in supporting the country's economy. Saudi Arabia is one of the major tourist destinations in this region. A report by Cordesman (2003) indicates that United Arabs Emirates and Saudi Arabia are the leading tourist destinations in this region. Saudi Arabia is a destination to a large number of Muslims who come to visit the two holy cities of Mecca and Medina. The two cities define the position of Saudi Arabia among the Arab world. Long (1997) say that Muslims across the world have an obligation to visit the city of Mecca at least once in their lifetime. The two cities have the greatest economic impact in Saudi Arabia, after oil and oil products. Cordesman (2003) observes, hundreds of thousands of Muslims around the world visit the two cities every year. When they come to the country, this scholar notes that they come as tourists. They have to spend in the hotels within the cities or their environs. This has seen the hospitality industry grow at a relatively high speed.

Although there are a number of foreign owned international hotels such as the Sheraton and Hilton in this country, there are several other local owned hotels and restaurants where these visitors can spend a night or two. These religious tourists come with the intention of meeting the obligation to visit the holy city of Mecca. However, from economic perspective, they are just tourists like any other. In fact, they make better tourists because they have no other choice but to visit the two cities (Baamir, 2010). This scholar further notes that when these tourists come, they will need to spend their cash within the country for transportation and upkeep. Some of them come with large families and therefore, they boost other sectors of the economy.

The entire world is currently subject to current changes brought about by technology. As Long (1997) notes, the current Arabic world is curving in to the western influence, though at a cautious pace. It is currently common to see a Muslim youth keenly engrossed on an American movie, something that was not there before. Because of this, they have adopted some western cultures that make them a little different from the traditional Muslims. The coming generation of Muslims is more tolerant and a little less conservative. This means that the social structure of the society is slowly changing as many youths embrace the Western culture.

\section{Methodology}

In a research project, it is always important to define the methodology that would be appropriate in yielding the most desirable results. In this research, a quantitative method was considered appropriate in collecting and analyzing data. The researcher used 150 participants within Riyadh who were from the banking sector. Stratified sampling method was used to select the sample population (Kothari, 2004). The strata used were defined by the number of years that a participant had been in the industry, the position held at various banking institutions, religious standings, and the possibility of an individual to have worked in the banking sector in other parts of the world (Anderson, 2009). In each stratum, simple random sampling was used to select specific individuals who would take part in the research. Care was taken to eliminate any form of bias at this stage.

Questionnaires were developed by the researcher to help in the collection of data from the participants 
(Calabrese, 2006). The questionnaire had four parts. The first part sought to capture the background information of respondents. The second part dealt with the demography and gender of the respondents. This was to ascertain the prevalence of views in various categories in order to ensure that if any differences came about, then they would be captured in their demographic space. The third part dealt with academic credentials and their understanding of issues about economic and social environment. The motivation for this section came from the understanding that different sections of population respond differently to issues, based on age and academic credentials. The fourth part delved into the specific issues relating to socio-economic background of Saudi Society and its impact on the financial sector.

The questionnaire employed a mix of open and closed ended questions to capture different aspects of issues studied. Open ended questions were used because they give respondents more time to figure out their opinions, which would make them volunteer more information related to feelings, outlooks and comprehension of the subject (Calabrese, 2006). This would allow a researcher to understand the position of respondents as regards to feelings. Open ended questions minimize some errors that could have been created in the course of research. Respondents rarely forget answers if given an opportunity to respond freely. Furthermore, respondents cannot ignore some questions because they must go through all of them. Open ended questions generate data that can be used in data analysis by other researchers. In other words, they allow secondary data analysis. On the other hand, closed-ended questions are analyzed easily. That is why they were used in this study (Kothari, 2004).

Each response can be coded for statistical interpretation. Nonetheless, closed-ended questions are compatible with computer analysis package. The technique is more specific meaning that its answers are consistent in all conditions. This aspect is impossible with open-ended questions because each respondent is allowed to use his or her own words. Finally, closed-ended questions take less time to administer unlike open-ended questions, which are detailed hence time consuming.

These questionnaires were sent to the sampled population through hand delivery. This was considered appropriate because the researcher needed to explain to them the relevance of this research and to convince them to take part in the research (Anderson, 2004). The physical delivery also created strong bonds and a sense of commitment between the researcher and the participants (Barthe \& Hermenegildo, 2010). The researcher for the purpose of analysis collected the answered questionnaires. Given that the research took quantitative approach, SPSS software was used to analyze data in order to arrive at various conclusions based on the hypotheses that were developed (Badenhorst, 2007). The researcher was keen to ensure that the validity and reliability of the data were upheld at all stages of research.

\section{Analyses and Discussion}

According to this research, it was confirmed that the social environment in this country still has a bearing on the banking behavior of the people of Saudi Arabia. Many people still believe that civilization that is not backed by religion is not only misleading and unacceptable, but also a practice that is meant to introduce a new culture that is strange in this society (Manaschi, 1998). According to the data obtained about the male and female employees of Samba Financial Group, it was clear that men felt more satisfied than women in their respective banks. The graph in Figure 1 below shows the result in tabular form.

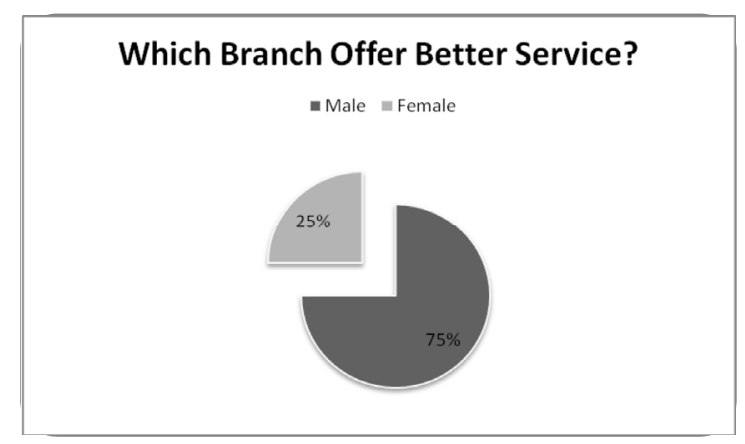

Figure 1. Which branch offers better service

The results that were obtained reveal that male customers enjoy superior services from the banks as compared to the female customers. This means that women would easily opt for home banking where they do not feel intimidated (Minja, 2009). This reduces the customer base of such financial institutions, a fact that would reduce 
their profitability. It also earns the firm a negative image in the international society. This means that the hypothesis below is confirmed.

Hla: The social-cultural environment in Saudi Arabia has a negative impact on the financial sector.

According to the results that were gathered from the respondents about the economic environment in this country, most of them noted that it had a positive impact on the financial sector. The data gathered was analyzed and presented graphically as shown in the figure 2 below.

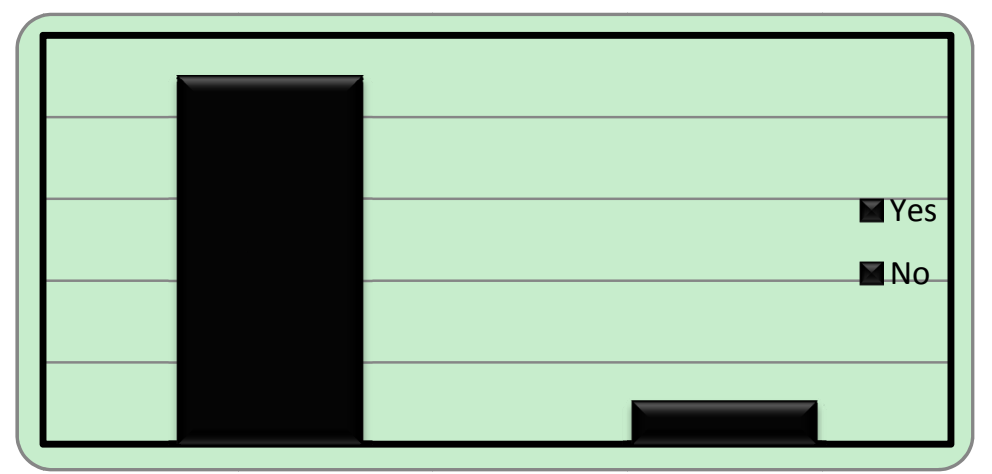

Figure 2. Do you believe that economic environment has positive impact on financial sector?

This confirms the second hypothesis below:

H2: The economic environment in Saudi Arabia has a positive impact on the financial sector.

This confirms that the economic environment in Saudi Arabia has had a positive impact on the financial sector of this country. They include such factors as tourism and the oil industries which are the major pillars of the country's financial sector.

\section{H3o: The religious practices in Saudi Arabia have not boosted the financial sector.}

The third hypothesis focused on the religious practices in the country, specifically the fact that Saudi Arabia is considered the cradle land for the Islamic society. This has seen many people come to the country for prayers. The data gathered from the field was analyzed and presented in the chart below.

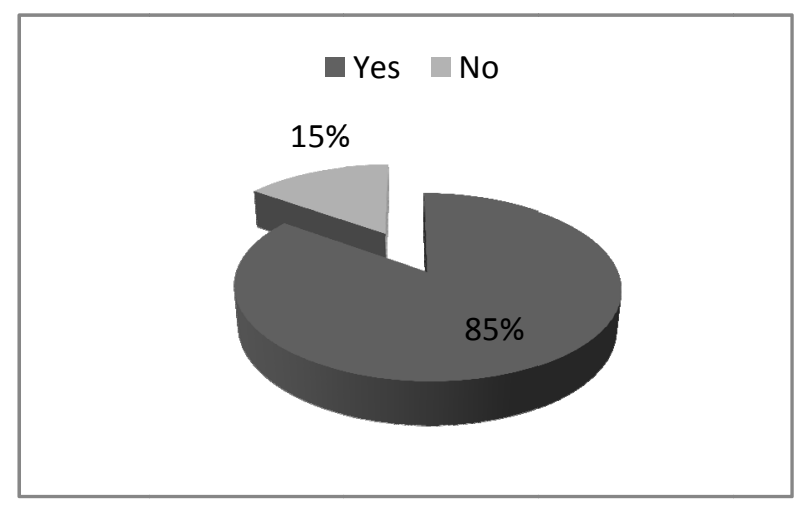

Figure 3. Do you believe that religious practices in the country has boosted the financial sector?

It is clear from the chart above that majority of the respondents felt that the religious practices in this countryspecifically the fact that many Muslims around the world visit the country regularly for spiritual nourishmentshas boosted the financial sector of the country. This confirms the alternative hypothesis below.

\section{H3a: The religious practices in Saudi Arabia have boosted the financial sector.}

The respondents were very specific on the issue about religion and its impact on the financial sector. Most of them observe that the pilgrimage that is popular in the city of Mecca attracts numerous visitors to the country on 
a yearly basis. When they come, they use the local financial institutions. Some of the frequent visitors have even considered opening bank accounts with the local financial institutions, boosting this sector of economy. It means that as the country continues to attract foreigners who visit the country for prayers, its financial sector will continue growing.

\section{Conclusion}

It is clear from the above discussion that the socio-economic environment in Saudi Arabia has a direct impact on the financial sector. The socio-cultural practices in this country have been determined to have a negative impact on this sector. Some of the cultural practices that lower the status of women in the society have been cited as one of the impediments that have to be fought to win this battle. This is so because it inhibits the ability of women to play a leading role in boosting the economy of the country. The analysis has indicated that the ability of the country to attract tourists around the world who come for religious purposes has boosted the financial sector of the country. The research shows that the economic environment in this country has helped to boost the financial sector in the country. The oil industry has played a major role in strengthening the financial sector. The country is the leading producer of oil, and most of the transactions are conducted through local financial institutions. Tourism is another factor that has boosted the economy. Others important industries include agriculture and retail sectors.

\section{References}

Al-Mulhim, N. (2009). Islamic Funding of Small Business in Saudi Arabia. Mumbai: McMillan Publishers.

Anderson, J. (2009). Assignment and thesis writing. Cape Town, Juta.

Anderson, V. (2004). Research Methods in Human Resource Management. London: Chattered institute of Personnel Management.

Baamir, A. Y. (2010). Shari' a Law in Commercial and Banking Arbitration: Law and Practice in Saudi. Burlington: Ashgate Publishing.

Badenhorst, C. (2007). Research writing: breaking barriers. Pretoria: Van Schaik Publishers.

Barthe, G., \&Hermenegildo, M. (2010). Verification, Model Checking, and Abstract Interpretation: 11th International Conference, VMCAI 2010, Madrid, Spain, 17-19, 2010, Proceedings. New York: Springer.

Behdad, S., \& Nomani, F. (2006). Islam and the Everyday World: Public policy Dilemmas. London: Routledge.

Belanger, C. (2011). Our World: Saudi Arabia. Riyadh: Cangage.

Calabrese, R. (2006). The elements of an effective dissertation and thesis: a step by step guide to getting it right the first time. Lanham: Rowman \& Littlefield.

Clinton, H. (2011). U.S Department of State, Diplomacy in Action. Washington, DC: Potomac Books, Inc.

Cordesman, A. (2003). Saudi Arabia Enters The 21st Century. New York: Greenwood Publishing Group.

Kent, M., \& Thompson, J. (2005). Economics of Banking. New York: John Wiley and Sons.

Kline, J. (2010). Ethics for International Business: Decision-Making in a Global Political Economy. New York: Routledge.

Kothari, C. R. (2004). Research methodology: Methods and techniques. New Delhi: New Age International (P) Limited Publishers.

Krivenko, E. (2009). Women, Islam and international law: within the context of the Convention on the Elimination of All Forms of Discrimination against Women. Danvers: Koninklijke Brill.

Lacey, R. (1982). The Kingdom: Arabia \& the House of Sa'ud. Harcourt Brace: Jovanovich.

Lippman, T. (2012). Saudi Arabia on the Edge: The Uncertain Future of an American Ally. Washington, DC: Potomac Books, Inc.

Lippman, W. (2004). Inside the Mirage: America's Fragile Partnership with Saudi Arabia. New York: West view Press.

Long, D. (1997). The Kingdom of Saudi Arabia. Gainesville: University Press of Florida.

Madawi, A. (2006). Contesting the Saudi State. Cambridge: Cambridge University Press.

Mai, Y. (2005). Changed Identities: The Challenge of the New Generation in Saudi Arabia. Columbia: University of British Columbia Press. 
Manaschi, A. (1998). Comparative Advantage in International Trade: A Historical Perspective. Cheltenham, UK: Edwards Elgar Publishing.

Minja, D. (2009). Ethical Practices for effective leadership: Fact or Fallacy- A case of Kenya.KCA Journal of Business Management, 2(1), 1-14. http://dx.doi.org/10.4314/kjbm.v2i1.44407

Nonneman, G. (2006). Saudi Arabia in the Balance: Political Economy, Society, Foreign Affairs. New York: New York University Press.

Robertson, B. (2005). Shaping the Current Islamic Reformation. London: Frank Class Publishers.

Rubin, B. (2005). Crises in the Contemporary Persian Gulf. New York: Routledge.

Shoult, A. (2006). Doing Business with Saudi Arabia. London: GMB Publishing Ltd.

Tollitz, N. (2005). Saudi Arabia: Terrorism, U.S. Relations, and Oil. New York: Nova Publishers.

Tripp, H. \& North, P. (2003). Saudi Arabia: Culture Shock Guides. New York: Graphic Arts Center.

\section{Copyrights}

Copyright for this article is retained by the author(s), with first publication rights granted to the journal.

This is an open-access article distributed under the terms and conditions of the Creative Commons Attribution license (http://creativecommons.org/licenses/by/3.0/). 